\title{
Breath-by-breath による肺胞ガス交換推定法
}

\author{
古賀 俊策 ${ }^{11}$, 対馬 清造 ${ }^{1)}$, 高橋 恒雄 ${ }^{2}$, 池上 晴夫 ${ }^{3}$ \\ 1) 秋田大学教育学部保健体育研究室 \\ 2) 秋由工業高等尃門学校保健体育科 \\ 3 ) 筑波大学体育科学系
}

\section{Breath-by-breath Estimation of Alveolar Gas Exchange}

\author{
Shunsaku Koga ${ }^{1)}$, Seizo Tsushima ${ }^{1)}$, Tsuneo TaKahashi ${ }^{2)}$ and Haruo Ikegami ${ }^{37}$ \\ 1) School of Education, University of Akita, Tegata, Akita-city, 010 \\ 2) Akita National College of Techrology, Iijima, Akita-city, 011 \\ 3) Institute of Health and Sports Sciences, The University of Tsukuba, Ibaragi-prefecture, 305
}

\begin{abstract}
We have developed a method that estimated breath-by-breath alveolar gas exchange by a compensation for changes in lung gas stores in studying respiratory transients during exercise. Inspiratory and expiratory flow signals were recorded with separate pneumotachographs. $\mathrm{CO}_{2}$ and $\mathrm{O}_{2}$ gas fractions were measured at the mouth continuously. A data acquisition program consisted of $\mathrm{A} / \mathrm{D}$ conversion of the respiratory signals and calculation of alveolar gas exchange variables. The correction for breath-by-breath changes in lung gas stores was applied to the total gas exchange which was obtained by subtracting expired from inspired gas volume. Incomplete or abnormal breath-by-breath dada were automatically inspected and edited either by combining with the previous or following incomplete companion breaths. The breath-by-breath variation in the gas exchange at the mouth was larger than the alveolar gas exchange, particularly in the transient state. The variation was attributed to the invalidity of the steady state gas uptake equations which assumed constant end-expiratory lung volume over a single respiratory cycle. However, during the steady state, the gas exchange at the mouth averaged to the same value as the alveolar gas exchange. The breath-by-breath analysis of alveolar gas exchange enables the investigator to study the transient and non -steady state responses to exercise.
\end{abstract}

Key words : Alveolar gas exchange during exercise, Respiratory transients, Non-steady state, Computerized system for breath-by-breath analysis

\section{I 。序 論}

運動時の生体反応は定常状態だけではなく, 非定常 状態を伴らことが多い。特に, 呼吸反応の過渡応答は 運動開始值後, 負荷強度の移行期, 無酸素性作業閾値 以上の負荷時において認められる。この様な呼吸反応 の過渡応答を調べるためには，口腔にお忛るガス交換 值だけではなく，肺胞のガス交換值を検討する必要が ある。肺胞ガス交換推定法では, 呼吸信号の誤差に対
するガス交換值の誤差感度が減少し, 呼吸毎のガス交 換値の変動が少なくなるので, 運動時の過渡応答の解 析には重要な手法となる。

しかし，口腔におけるガス交換值を測定する呼気流 速法の誤差に加えて, 肺胞ガス交換推定法では, 吸気 量の測定, 肺容量の推定, 肺ガス貯留量の演算アルゴ リズムの作成を行う際に, 種々の誤差が問題となる。 この報告では, 肺胞ガス交換推定装置のシステムを 
説明し，その方法の問題点を考察した。

\section{II. 方 法}

著書たちは既に他の報告（古賀ら，1985）において， 呼気流速法によるbreath一by一breath のガス交換測 定装置の紹介をしている。今回の報告では测定装置の 校正，フィルタリングなど重複する筒所は省略して， 肺胞ガス交換推定法について説明をした。

呼気流速および吸気流速の測定をするために呼吸バ ルブの呼気側と吸気側に，それぞれ Fleisch 型ニュー モタコグラフ, 差圧変換器 (Validyne, MP45-1), 搬送波堌幅器を備えた。 $\mathrm{CO}_{2}, \mathrm{O}_{2}$ 濃度測定には, Applied Electrochemistry 社の $\mathrm{CO}_{2}$ 分析計 $(\mathrm{CD}-3$ A), $\mathrm{O}_{2}$ 分析計 $(\mathrm{S}-3 \mathrm{~A})$ を用いた。

演算処理は一次計算処理と二次計算処理によって構 成され，一次計算処理で呼吸気流速，ガス濃度，心電 図, 採気ガス温度, 運動負荷の信号を $\mathrm{A} / \mathrm{D}$ 変換して, SHARPの MZー80Cシステム，または NEC 日本電 気のPC-9801VM2システムで演算処理した。

二次計算処理にはPC-9801VM2システムを用い た。一次計算処理にSHARP の MZー80Cシステムを 採用した場合には，MZ一PCデータファイルコンバー ターによって二次計算処理用にファイル変換を実行し た。一次計算のデータファイルを乎気ガスデータと吸 気ガスデータに分け，各々のファイルに流速信号の積 分値，流速信号とガス濃度信号の乗算の積分値，一回 呼吸時間, 呼気時間および吸気時間, $\mathrm{CO}_{2}$ 濃度信号の最 大値, $\mathrm{O}_{2}$ 濃度信号の最小値, 流速信号のベースライン, 心電図信号の $R-R$ 間隔, 採気ガス温度, 負荷強度, 呼吸認識終了のデータを甾き込んだ。

この後, 一次計算データをディスクファイルより読 出出し, 二次計算処理として肺胞ガス交換値の推定を 行った。演算アルゴリズムは従来の研究による方法 (Beaver et al., 1981) に従い, 吸気ガス量と呼気ガス 量の差沛肺ガス貯留量の補正をするものである。従来 用いられてきたbreath一by一breathによるガス交換 測定法は呼気相の流速とガス濃度だけを測定する呼気 流速法であり，呼吸毎の呼気終末肺容量を一定として 口腔における窒素平衡を仮定する。しかし，この方法 で用いる窒素平衡の式は，定常状態に抢ける複数の呼 吸の平均的なガス交換動態に適用されるものであり， 呼吸毎のガス交換動態は過渡状態だけでなく定常状態
においても肺容量の変動の影響を受ける。したがって， 肺胞ガス交換推定の演算アルゴリズムでは, 吸気ガス 量を実測して，口腔に扮けるガス交換值 $\left(\mathrm{V}_{\mathrm{gas}}\right)_{\mathrm{M}}$ を求 め，肺がス貯留量の変動（ $\Delta \mathrm{V}_{\mathrm{Lgas}} ）$ を補正する。

$$
\left(\mathrm{V}_{\text {gas }}\right)_{\mathrm{M}}=\int \mathrm{F}_{\text {Igas }} \cdot \dot{\mathrm{V}}_{\mathrm{I}} \mathrm{dt}-\int \mathrm{F}_{\mathrm{Egas}} \cdot \dot{\mathrm{V}}_{\mathrm{E}} \mathrm{dt}
$$

肺胞におけるガス交換值 $\left(V_{\text {gas }}\right)_{A}$ は

$$
\left(\mathrm{V}_{\text {gas }}\right)_{\mathrm{A}}=\left(\mathrm{V}_{\text {gas }}\right)_{\mathrm{M}}-\Delta \mathrm{V}_{\text {Lgas }}
$$

となる。 $\Delta \mathrm{V}_{\mathrm{Lgas}}$ は肺容量 $\left(\mathrm{V}_{\mathrm{L}}\right)$, 肺胞ガス濃度 $\left(\mathrm{F}_{\mathrm{Agas}}\right)$ とそれらの変化量 $\left(\Delta \mathrm{V}_{\mathrm{L}}, \Delta \mathrm{F}_{\mathrm{Ag} \text { as }}\right)$ 上り求める。

$\Delta \mathrm{V}_{\mathrm{Lgas}}=\Delta \mathrm{F}_{\mathrm{Agas}} \cdot \mathrm{V}_{\mathrm{L}}+\Delta \mathrm{V}_{\mathrm{L}} \cdot \mathrm{F}_{\mathrm{Agas}}$

$\Delta \mathrm{V}_{\mathrm{L}}$ は肺へ吸入されるガスの総量から呼出されるが スの総量を差し引いて求めた。次に，口腔における窒 素交換量 $\left(\dot{\mathrm{V}}_{\mathrm{N} 2}\right)$ を計算するために, 吸気量 $\left(\mathrm{V}_{\mathrm{I}}\right)$ と呼 気量 $\left(\mathrm{V}_{\mathrm{E}}\right)$ を実測するとともに $\mathrm{CO}_{2}, \mathrm{O}_{2}$, 水蒸気濃度 から平均混合 $\mathrm{N}_{2}$ 濃度を推定した。呼吸気の平均混合

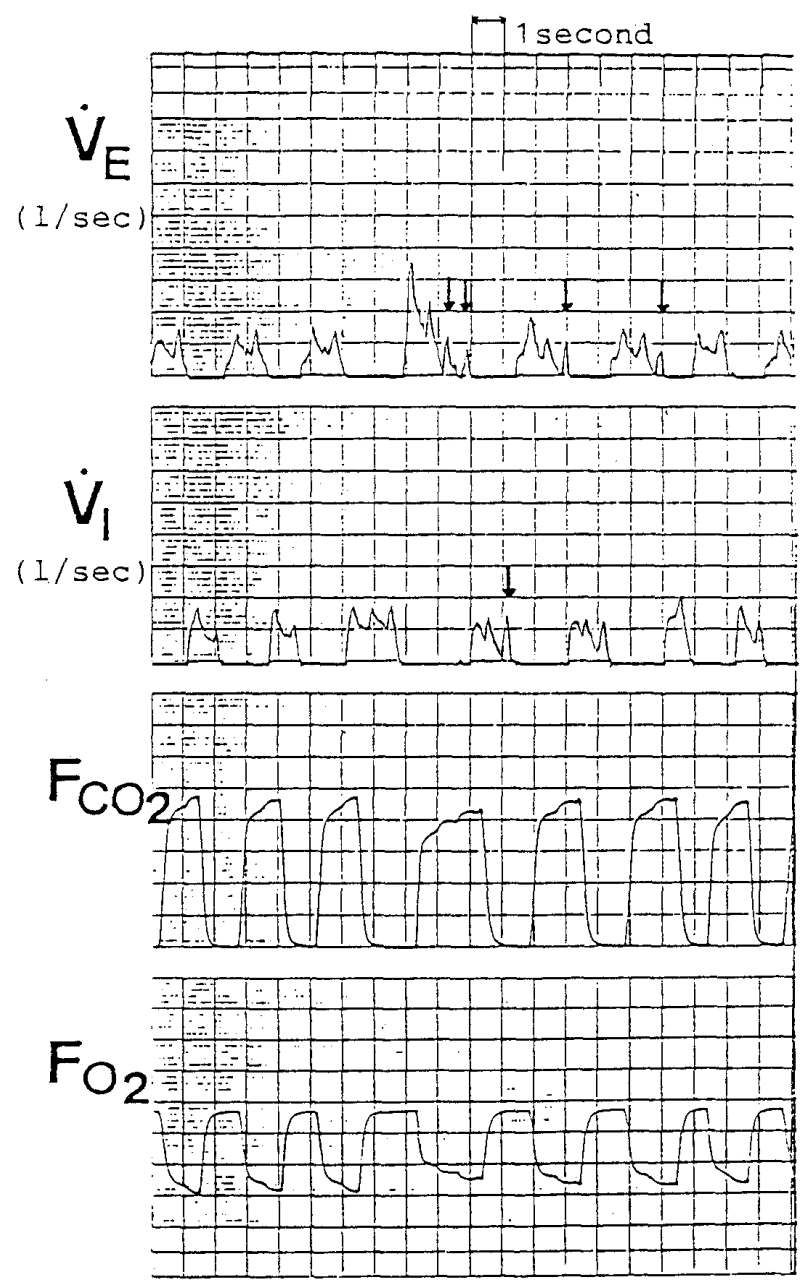

Fig. 1 Expiratory flow $\left(\dot{\mathrm{V}}_{\mathrm{E}}\right)$, inspiratory flow $\left(\dot{\mathrm{V}}_{\mathrm{I}}\right)$, $\mathrm{CO}_{2}$ and $\mathrm{O}_{2}$ gas fractions during exercise. Arrows indicate incomplete breaths. 
$\mathrm{CO}_{2}, \mathrm{O}_{2}$ 濃度は一次計算処理で求めた流速とガス濃度 信号の乗算の積分值 $\left(\mathrm{V}_{\mathrm{ECO} 2}, \mathrm{~V}_{\mathrm{EO} 2}, \mathrm{~V}_{\mathrm{ICO} 2}, \mathrm{~V}_{\mathrm{IO} 2}\right)$ をそ れぞれ $V_{E}$ と $V_{I}$ で除することによって求めた。また，呼 気終末の肺容量には， $\mathrm{N}_{2}$ 洗い出し法によって得られた 安静時の機能的残気量を用いた。

この様にして推定された肺胞のガス交換値には不完 全あるいは異常呼吸のデータが含まれるので（図 1 ),

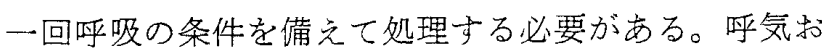
よび吸気の認識においては，流速信号のベースライン の記録や呼吸認識終了時のトリガーパルスを参考にし て，ある一定の流速信号閾值を設定した。今回の報告 では呼気，吸気ともに最大流速設定值に対して，1\% の值を示す流速信号䦪値を設定し，認識時間として50 $\mathrm{ms}$ を要した。一回呼吸の条件としては， $V_{1}$ と $V_{\mathrm{E}}$ がそ れぞれ $150 \mathrm{ml}$ 以上，一回呼吸時間が 0.8 秒以上（呼吸 数が每分75回以下), 吸気量と呼気量の比 $\left(\mathrm{V}_{\mathrm{I}} / \mathrm{V}_{\mathrm{E}}\right)$ が 0.5〜2.0までの範囲としだ。したがってこのような 条件によって不完全ないしは異常呼吸として認識され たデータを前後の乎気または吸気データに加える様, 補正プログラムを作成した。さらに各呼吸の呼気と吸
気の組合せのずれをらせぐために，呼気相の終了時刻 之吸気相の開始時刻の一致, 毎分の呼気相の数と吸気 相の数の一致を確認させた。図 2 に不完全あるい潩 常呼吸データに対する処理として，呼気相と吸気相の 時間照合を行らコンピューターのスクリーン上でのエ ディットを例示した。この図の上段には横軸に任意の 時刻をとり，縦軸に呼気量と吸気量の程度を表した。 下段には各乎吸の番号に対応して，乎吸気のデータを 表示した。

二次計算処理で求めた肺胞がス交換諸量は $\dot{\mathrm{V}}_{\mathrm{E}}, \dot{\mathrm{V}}_{\mathrm{I}}$, $\mathrm{V}_{\mathrm{T}}$ (一回換気量), $\dot{\mathrm{f}}$ (四吸数)， $\mathrm{P}_{\mathrm{ETCO} 2}$ (呼気終末 $\mathrm{CO}_{2}$ 分 E), $\mathrm{P}_{\mathrm{ETO} 2}$ (呼気終末 $\mathrm{O}_{2}$ 分圧)， $\dot{\mathrm{V}}_{\mathrm{CO} 2}, \dot{\mathrm{V}}_{\mathrm{O} 2}, \mathrm{R}$ (呼吸ガ 不交換率)， $\dot{\mathrm{V}}_{\mathrm{E}} / \dot{\mathrm{V}}_{\mathrm{CO} 2}, \dot{\mathrm{V}}_{\mathrm{E}} / \dot{\mathrm{V}}_{\mathrm{O} 2}, \mathrm{HR}$ (心拍数)であっ た。この他に, 平均混合がス濃度, $\dot{\mathrm{V}}_{\mathrm{N} 2}$ とともに $\Delta \mathrm{V}_{\mathrm{L}}$, $\Delta \mathrm{F}_{\text {Agas }}$ など肺ガス貯留量に関連するデータも二次計算 のデータファイルに書き込んだ。

二次計算のデータファイルはグラフ表示と統計解析 に用いるので，一回呼吸毎，または一定の時間間隔の 値に換算して処理した。呼気流速法による一回呼吸每 のガス交換法では不規則呼吸の影響を受けて変動が生

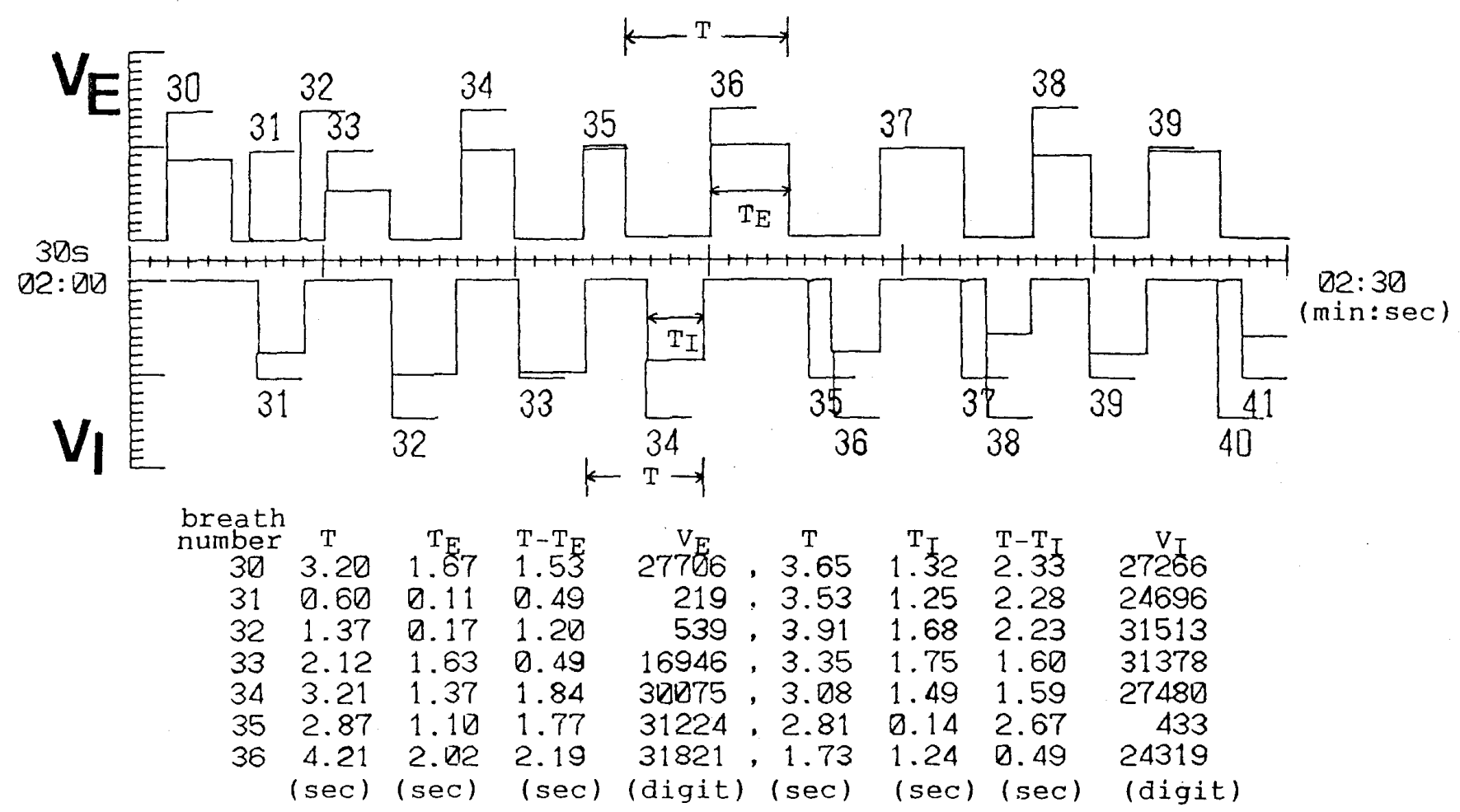

Fig. 2 Automatic inspection and edition for incomplete breaths. An incomplete breath was identified and edited by the following data: breath duration $(T)$, expiratory time $\left(T_{E}\right)$, inspiratory time $\left(T_{I}\right)$, expiratory volume $\left(V_{E}\right)$, and inspiratory volume $\left(V_{I}\right) . V_{E}$ and $V_{I}$ were expressed as $\mathrm{A} / \mathrm{D}$ unit (digit). 
じるので，移動平均あるい性数呼吸の平均値によって 平滑化処理を実行した。しかし，肺胞がス交換推定法 では肺ガス貯留量の補正をするので平滑化処理を加文 なかった。

一回呼吸毎のデータのグラフ表示は, 肺胞ガス交換 値だけの表示, あるいは呼気流速法で求めた口腔のガ 不交换値と比較する表示にした。さらに，口腔にお汁 る窒素平衡を仮定して推定した吸気量と実測した吸気 量の比較表示もできるようにした。

任意の時間間隔のデータ表示については, ダグラス バッグ法による測定值, 呼気流速法による演算值を肺 胞ガス交換値と比べるために, 分時平均值の計算を 行った。また, 個人内の呼吸毎の変動をみるために標 準偏差の計算もした。さらに, 被験者あるいは運動負 荷強度の違いによるガス交換値を比較するために，5 秒毎の値に換算し, 平均値, 標準偏差を計算した。

統計解析の方法として, ガス交換諸量の相関, 回帰 分析, 多変量解析, 有意差検定を用いた。この他, 一 回呼吸毎のガス交換動態を近似曲線として表わすため に，最小二乗法による演算をした。

\section{III. 結果と考察}

最初に呼気流速法で求めた口腔のガス交換值と肺胞
におけるガス交換值を図 3 に示した。6分間の50ワッ ト（W）負荷に続く6 分間の一定強度負荷 (250W) を 用い，回復期には，6分間の50W 負荷を課した。負荷 の移行期では, ガス交換動態は過渡状態にあり, 肺胞

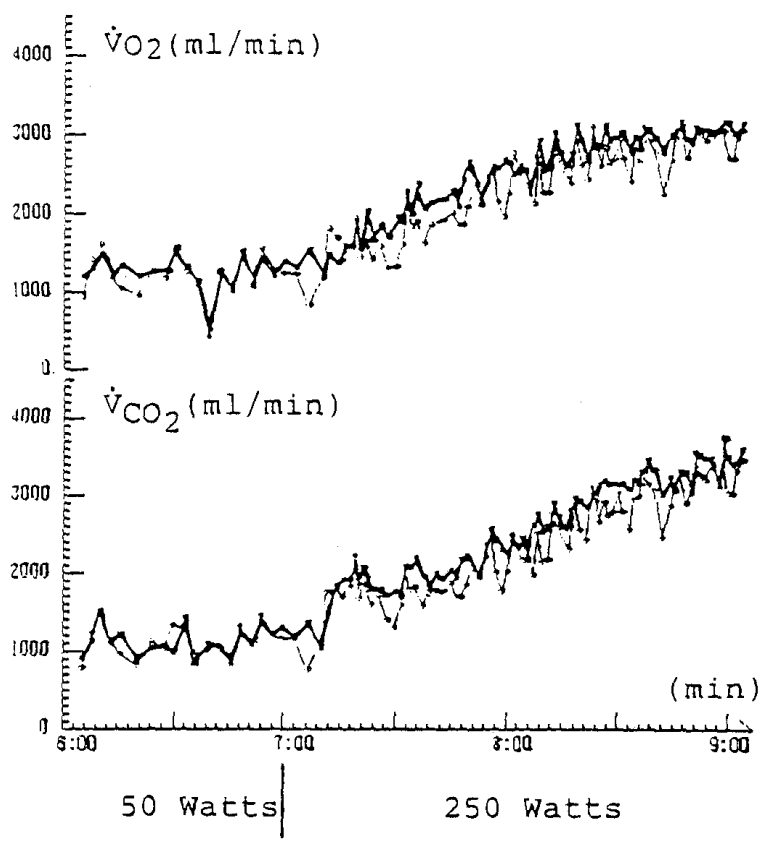

Fig. 3 Breath-by-breath gas exchange kinetics measured at the mouth (thin lines) and estimated at the alveolar level (heavy lines) during a work load transition between $50 \mathrm{~W}$ and $250 \mathrm{~W}$.

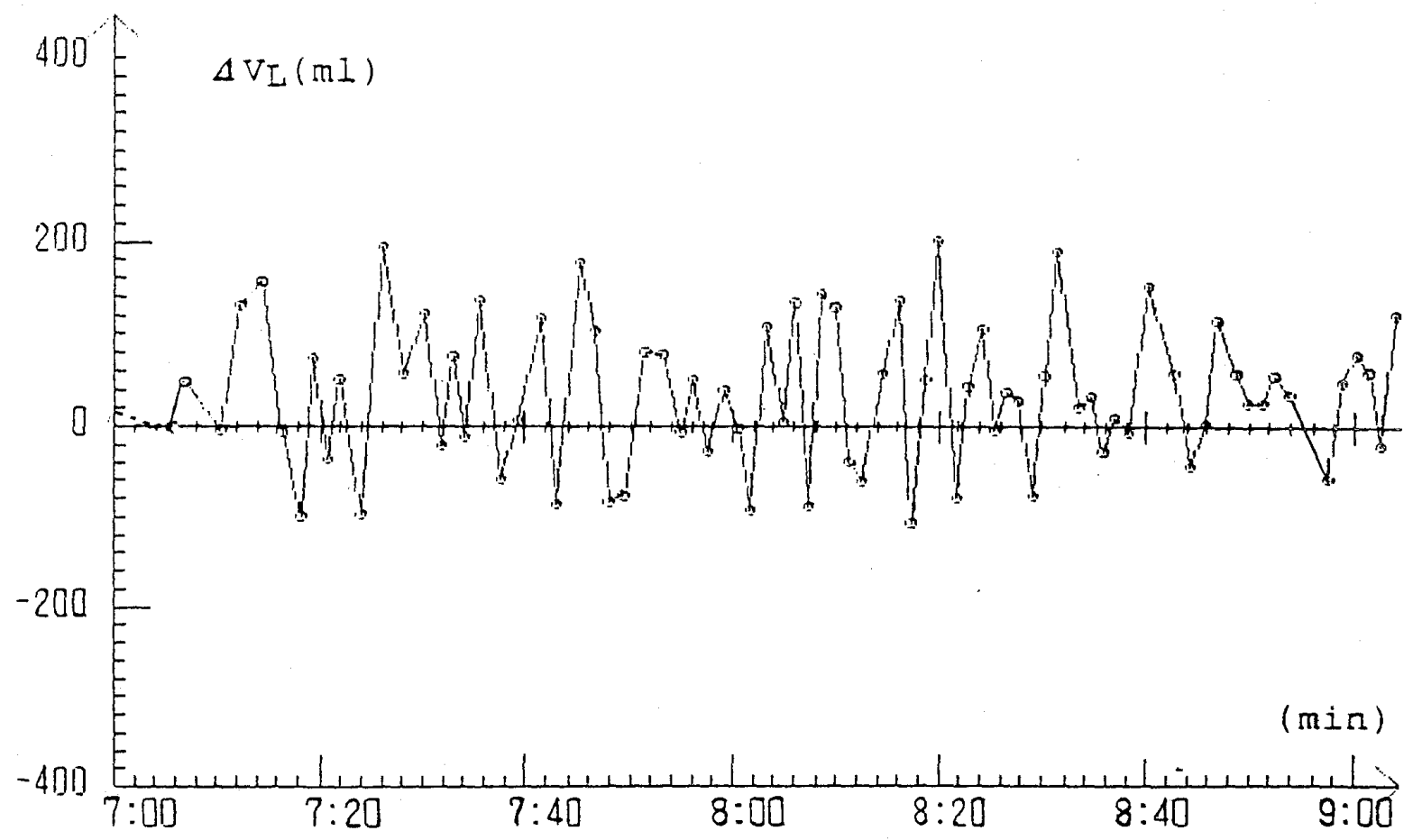

Fig. 4 Breath-by-breath changes of $\Delta \mathrm{V}_{\mathrm{L}}$ during $250 \mathrm{~W}$ work. 
におけるガス交換值はロ腔における値よりも高い傾向 を示した。この他の負荷例では，肺胞値の呼吸毎の変 動が口腔值に比べて少ないことが示されだ。この原因 としては前述の様に呼吸毎の呼気終末肺容量を一定と してロ腔における窒素平衡を仮定したことが考えられ た。 $\Delta \mathrm{V}_{\mathrm{L}}$ は図 4 の様に呼吸毎に変動し，口腔における $\dot{\mathrm{V}}_{\mathrm{I}^{2} 2}$ に影響を与えた。定常状態においても $\dot{\mathrm{V}}_{\mathrm{N} 2}$ はゼ口 ではなかった。

しかし, 定常状態期における複数の呼吸の平均值や 分時平均值を比べた場合, 肺胞ガス交換値は口腔のガ ス交換値と有意な差を示さなかった。Beaver et al. (1981)は一回呼吸毎の肺ガス貯留量の変動が一定期間 にわたって累積される場合, 平均的には肺ガス貯留量 は一定となり, 肺胞値と口腔值が近似することを指摘 した。

肺ガス眝留量の変動は(3)式の様に $\Delta \mathrm{F}_{\mathrm{Agas}} \cdot \mathrm{V}_{\mathrm{L}}$ と $\Delta \mathrm{V}_{\mathrm{L}} \cdot \mathrm{F}_{\mathrm{Agas}}$ の項によって補正されるが，肺容量 $\left(\mathrm{V}_{\mathrm{L}}\right)$ については，現在のところ安静時の機能的残気量の実 測値ないしは予測値を用いることが一般的となってい る。 $\Delta \mathrm{F}_{\mathrm{Agas}} \cdot \mathrm{V}_{\mathrm{L}}$ の項は $\Delta \mathrm{F}_{\mathrm{Agas}}$ の值が小さく無視される 報告（Wessel et al；1983，1984）もあるが，呼吸毎 のガス交換値の変動が増加し, 過渡応答を過少評価す

る(Swanson and Sherrill 1983)。

肺胞におけるガス交換値を推定する場合, 口腔で測 定する呼気終末ガス濃度を肺胞ガス濃度の代表値とす るが, 肺の換気, 血流分布が肺胞ガス濃度の均等性へ
及ぼす影響について考慮する必要がある(Wessel et al. 1979)。

肺胞と口腔のガス交換の差は肺ガス貯留量, 特に肺 容量の変動 $\left(\Delta \mathrm{V}_{\mathrm{L}}\right)$ によって生じるが, $\Delta \mathrm{V}_{\mathrm{L}}$ は吸気量 之呼気量の差, $V_{\mathrm{I}}-\mathrm{V}_{\mathrm{E}}$ に近似する。定常状態において は，呼吸住概して規則的であるが，非定常状態，過渡 状態では不規則になり， $V_{1}-V_{\mathrm{E}}$ の時間平均值は正また は負の方向へ傾くことがある。この傾向は個人毎の呼 吸パターンの影響によるものであり，ガス交換動態上 の関連を今後検討する必要がある。

今回の方法では，一回呼吸毎のガス交換諸量の相関 関係を考察することが可能であり，定常状態だけでは なく，非定常状態における換気，呼吸調節の研究に有 用なデータを提供すると考えられる。Wassernan と Whipp（1983）は中強度の運動時では, 定常状態, 非 定常状態のいずれにおいても $\dot{\mathrm{V}}_{\mathrm{E}}$ が $\dot{\mathrm{V}}_{\mathrm{CO} 2}$ と密接に関連 していることを報告したが，一方では $\dot{\mathrm{V}}_{\mathrm{O} 2}$ と $\dot{\mathrm{V}}_{\mathrm{CO} 2}$ に対 する相関が $\dot{\mathrm{V}}_{\mathrm{E}}$ よりも $\dot{\mathrm{V}}_{\mathrm{I}}$ の方が高いとする報告すある (Wessel et al., 1978, 1979)。図 5 にはランプ負荷に おける $\dot{\mathrm{V}}_{1}$ と $\dot{\mathrm{V}}_{\mathrm{CO} 2}, \dot{\mathrm{V}}_{\mathrm{O} 2}$ の相関を示した。この例では, $\dot{\mathrm{V}}_{\mathrm{I}}$ は $\dot{\mathrm{V}}_{\mathrm{CO2}}$ よりも $\dot{\mathrm{V}}_{\mathrm{O} 2}$ に対して相関が高いことが示さ れた。 $\dot{\mathrm{V}}_{02}$ は吸気 $\mathrm{O}_{2}$ 量と呼気 $\mathrm{O}_{2}$ 量の差より求められる ことから、 $\dot{\mathrm{V}}_{\mathrm{E}}$ だけではなく, $\dot{\mathrm{V}}_{\mathrm{I}}$ の影響を強く受けると 考えられる。

非定常状態におけるガス交換諸量の相関を研究する ことは, 呼吸生理学の面において重要である。さらに,
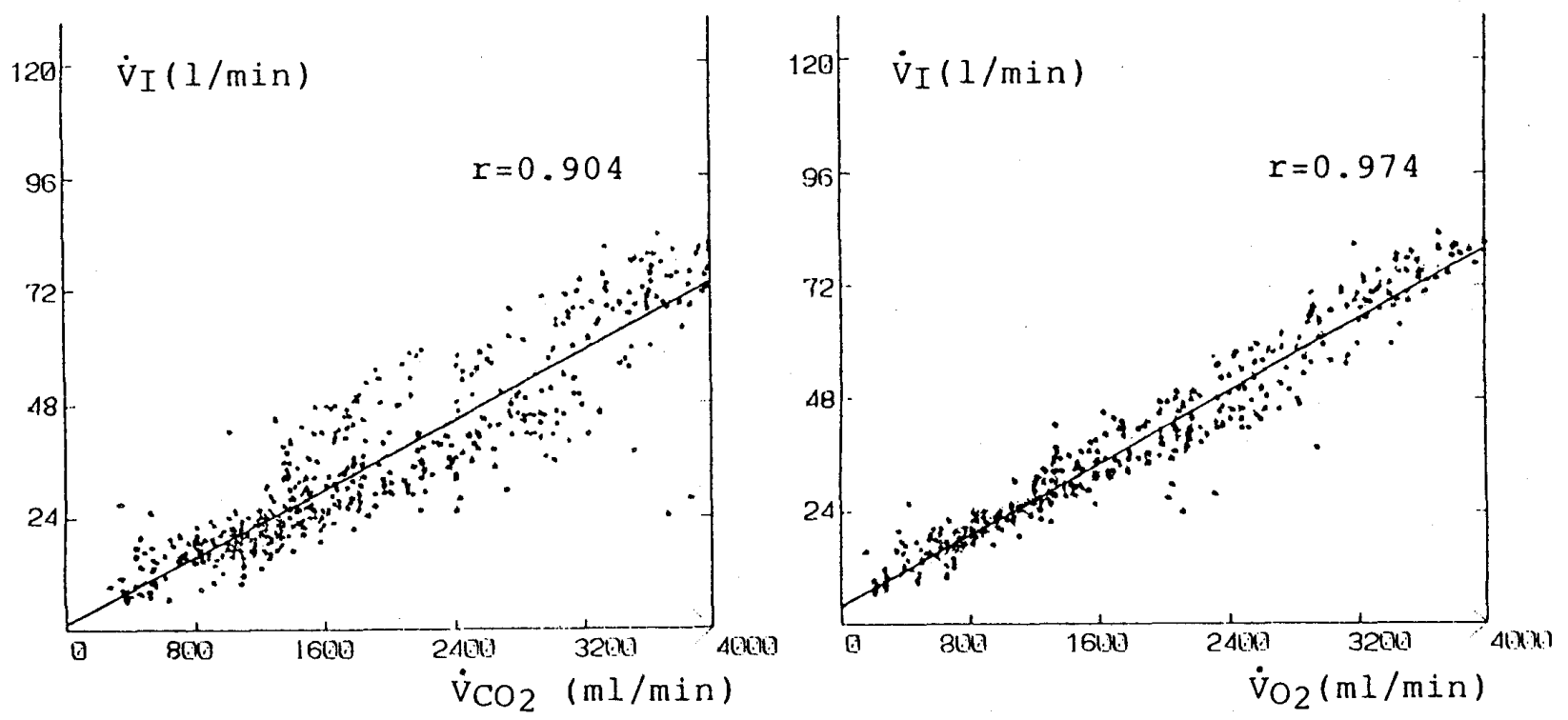

Fig. $5 \dot{V}_{1}$ is plotted as function of $\dot{V}_{\mathrm{co} 2}$ and $\dot{V}_{\mathrm{o} 2}$ for ramp work test in a normal subject. 
通常の運動負荷検査で得た定常状態の生体情報を，非 定常状態を伴う実際の日常運動に適用する是非を検討 する上です意義がある。

肺胞ガス交換推定法によって，過渡状態にお汀るガ ス交換動態，吸気量と呼吸調節，呼吸パターンとガス 交換動態などの検討が可能となり，呼気流速法に比べ て数多くの呼吸データが得られることはこの方法の大 きな利点であろう。

\section{文 献}

Beaver, W.L., N., Lamarra, and K. Wasserman. 1981 : Breath-by-breath measurement of true alveolar gas exchange. J. Appl. Physiol. : Respirat. Environ. Exercise Physiol., 51 (6) : 1662-1675.

古賀俊策, 対馬清造, 高橋恒雄, 池上晴夫. 1985 ：

Breath-by-breath によるガス交換測定法における 問題点の検討, 体力科学. 34(2): 75 90.

Swanson, G.D., and D.L. Sherrill. 1983 : A model evaluation of estimates of breath-to-breath alveolar gas exchange. J. Appl. Physiol. : Respirat. Environ. Exercise Physiol., 55 (6) : 1936-1941.

Wasserman, D.H., and B.J. Whipp. 1983 : Coupling of ventilation to pulmonary gas exchange during nonsteady-state work in men. J. Appl. Physiol. : Respirat. Environ. Exercise Physiol., 54 (2) : 587 $-593$.

Wessel, H.U., R.L. Stout, and M.H. Paul. 1978 : Minicomputer based system for breath-by-breath analysis of ventilation and pulmonary gas exchange. Proc. 5th Annu. Conf. Comp. Cardiol. IEEE Comput. Soc., Long Beach, CA : 97-104.

Wessel, H.U., R.L. Stout, C.K. Bastanier, and M.H. Paul. 1979 : Breath-by-breath variation of FRC : effect on $\dot{\mathrm{V}}_{2}$ and $\dot{\mathrm{V}}_{\mathrm{CO}_{2}}$ measured at the mouth. J. Appl. Physiol. : Respirat. Environ. Exercise Physiol., 46 (6) : 1122-1126.

Wessel, H.U., R.L. Stout, and M.H. Paul. 1983 : Breath-by-breath determination of alveolar gas exchange (Letter to the editor). J. Appl. Physiol: Respirat. Environ. Exercise Physiol., 54 (2) : 598 -599 .

Wessel, H.U., R.L. Stout, and M.H. Paul. 1984 : On the breath-to-breath estimation of gas exchange (Letter to the editor). J. Appl. Physiol. : Respirat. Environ. Exercise Physiol., 56 (1) : 260.

（1986年 9 月 2 日受付） 